\title{
Blood lipid concentrations and other cardiovascular risk factors: distribution, prevalence, and detection in Britain
}

\author{
J I MANN， B LEWIS， J SHEPHERD， A F WINDER，S FENSTER， L ROSE， B MORGAN
}

\begin{abstract}
To establish the distribution of blood lipid concentrations and the prevalences of other risk factors for cardiovascular disease in Britain 12092 men and women aged 25-59 in Glasgow, Leicester, London, and Oxford were studied. Subjects were selected by opportunistic case finding, in which patients consulting their general practitioner for any reason were offered a health check by appointment, or random selection from age-sex registers, in which an invitation for a health check was posted. The overall rate of response was $73 \%$, being $91-94 \%$ by opportunistic case finding and $36-63 \%$ by random selection. At the health check subjects answered a brief questionnaire about risk factors for cardiovascular disease, and their height, weight, and blood pressure were recorded; a blood sample was taken for measuring plasma concentrations of cholesterol, triglyceride, high density lipoprotein cholesterol, and glucose.

The mean cholesterol concentrations were 5.9 (SD 1.2) and $5.8(1.2) \mathrm{mmol} / \mathrm{l}$ in men and women, respectively. In London the mean value was $5.5(1.2) \mathrm{mmol} / \mathrm{l}$ for both men and women and was significantly lower than mean values in the three other centres, among which there were no significant differences. In men and women aged 25-29 concentrations were similar but they increased in men until the age of 45-49, after which they showed no further increase; in women concentrations did not increase until the age of 40-44 and by the age of 50-59 values were higher tharr in men. Mean triglyceride concentrations were significantly higher in men than in women $(1.8(1.4)$ v $1.3(0.9) \mathrm{mmol} / \mathrm{l}$, respectively), and trends with age were similar to those for cholesterol concentrations, except that at no age were values higher in women than in men. Mean triglyceride values overall were higher in Glasgow and London than in Oxford and Leicester. Body mass index was higher in Glasgow and London than in the other two centres and correlated with systolic and diastolic blood pressures and triglyceride concentration. In addition, subjects in Glasgow smoked significantly more than those in the other centres. These observations could contribute to the higher rate of coronary heart disease in Glasgow. Plasma lipid concentrations and the prevalences of other risk factors for
\end{abstract}

Department of Community Medicine, University of Oxford

J I MANN, DM, PHD, lecturer (also honorary consultant physician at John Radcliffe Hospital)

B MORGAN, SRN, research nurse

Department of Chemical Pathology and Metabolic Diseases, United Medical and Dental Schools of Guy's and St Thomas's Hospitals, St Thomas's Hospital, London SE1 7EH

B LEWIS, FRCP, FRCPATH, professor

Department of Chemical Pathology, University of Glasgow, Glasgow Royal Infirmary, Glasgow G4 0SF

J SHEPHERD, MD, PHD, professor

Leicester Royal Infirmary and Faculty of Medicine, University of Leicester

A F WINDER, DM, FRCPATH, consultant chemical pathologist and honorary reader in pathology

Bristol Myers Pharmaceuticals, Uxbridge UB10 8NS

S FENSTER, MSC, research manage

L ROSE, BSC, MIBIOL, medical services manager

Correspondence to: Professor J I Mann, Nutrition Department, University of Otago, PO Box 56, Dunedin, New Zealand. cardiovascular disease were similar in subjects selected by opportunistic case finding and by random selection.

In Britain cholesterol values have changed little during the past 12 years despite dietary recommendations and health education. Identifying subjects at particularly high risk of coronary heart disease is required to supplement advice to the general population to reduce the prevalence of this disease. Opportunistic case finding would be an appropriate method of identifying such subjects in general practice, although none of the potential markers for hyperlipidaemia was particularly useful in identifying all subjects at high risk.

\section{Introduction}

Little up to date information is available about the distribution of blood lipid concentrations and the prevalences of other cardiovascular risk factors in Britain. In 1974 Lewis et al reported mean cholesterol concentrations of 5.8 and $5.9 \mathrm{mmol} / \mathrm{l}$ in men and women, respectively, aged $20-59$ years and that $4 \cdot 3 \%$ of men and $4.8 \%$ of women had serum cholesterol concentrations greater than $7 \cdot 8 \mathrm{mmol} / 1 .{ }^{1}$ More recent studies investigated selected populations (male factory workers, ${ }^{2}$ male civil servants, ${ }^{3}$ and men having medical tests for insurance purposes ${ }^{4}$ ), and the regional heart study investigated risk factors in men aged $40-59$ years. ${ }^{5}$ Strategies for preventing premature coronary heart disease include measures directed to the population as a whole and those directed to individual subjects at high risk. ${ }^{6}$ In planning for both the population and the high risk strategies the prevalence of the major risk factors for coronary heart disease in men and women must be known. Our study was designed to provide this information and compare techniques of case finding that might be useful in implementing the strategy for individual subjects in general practice.

Subjects and methods

\section{RECRUITMENT}

The study was based in four British centres: Glasgow, Leicester, London, and Oxford. It was approved by each centre's ethical committee. General practices were selected because patients on their practice lists were considered to be representative of the social class structure of the city and the general practitioners were enthusiastic about participating and prepared to interact with a teaching hospital and its lipid laboratory and lipid clinic. Nurses trained in the lipid clinics examined patients for risk factors for coronary disease, sometimes with a doctor. Men and women aged 25-59 years were eligible for the study, and potential participants were excluded only because of a major or lifethreatening illness. In Glasgow the age-sex register of the large hospital based general practice was repeatedly sampled until all eligible people had been invited. In Leicester and Oxford two methods of recruitment were used in different practices. In those practices undertaking "opportunistic case finding" patients attending the surgery for any reason were offered a health check that entailed returning by appointment for a 15 minute examination. In other practices invitations for the health check were posted to eligible subjects randomly identified from age-sex registers ("random selection"). In London opportunistic case finding and random selection were carried out in the same practices. Rates of response varied among the centres: $91-94 \%$ responded to opportunistic case finding, and $36-63 \%$ of those randomly selected attended for screening. The overall rate of response was $73 \%$. Table I shows the numbers of subjects recruited in each of the centres; 6011 subjects were recruited by opportunistic case finding and 6081 by random selection.

Two approaches were used to determine whether the participants were representative of the population from which they were drawn. Firstly, 
TABLE I-Numbers of subjects recruited in each centre

\begin{tabular}{|c|c|c|c|c|c|c|c|c|c|}
\hline \multirow{2}{*}{$\begin{array}{c}\text { Age } \\
\text { group } \\
\text { (years) }\end{array}$} & \multicolumn{2}{|c|}{ Oxford } & \multicolumn{2}{|c|}{ London } & \multicolumn{2}{|c|}{ Leicester } & \multicolumn{2}{|c|}{ Glasgow } & \multirow[b]{2}{*}{ Total } \\
\hline & Men & Women & Men & Women & Men & Women & Men & Women & \\
\hline $25-34$ & 282 & 321 & 271 & 285 & 192 & 257 & 463 & 420 & 2491 \\
\hline $35-44$ & 803 & 907 & 205 & 269 & 433 & 459 & 479 & 481 & 4036 \\
\hline $45-54$ & 633 & 658 & 246 & 281 & 415 & 449 & 591 & 654 & 3927 \\
\hline $55-59$ & 194 & 208 & 121 & 108 & 203 & 168 & 310 & 326 & 1638 \\
\hline Total & 1912 & 2094 & 843 & 943 & 1243 & 1333 & 1843 & 1881 & 12092 \\
\hline
\end{tabular}

results obtained using the two methods of recruitment were compared. Secondly, in some practices that used random selection a sample of patients who did not respond to the posted invitation were followed up and agreed to be examined. Information obtained from these patients was compared with that from those who responded to the initial invitation.

\section{ASSESSMENT OF RISK FACTORS}

Assessment comprised a brief questionnaire about personal and family history of coronary heart disease, other relevant medical history, smoking habits, therapeutic diets, and drug treatment. Weight (with outdoor clothing removed) and height were recorded. Blood pressure was measured with ordinary mercury sphygmomanometers to Korotkoff phase $\mathrm{V}$ on the non-dominant arm while patients were sitting and after they had rested for five minutes. Nurses who had been trained at the participating lipid clinic examined the patients for corneal arcus, xanthelasmas, and xanthomas; positive findings were subsequently corroborated by a doctor from the lipid clinic. A blood sample was taken without prolonged venous occlusion after patients had been sitting for five minutes. This was for measuring plasma concentrations of cholesterol, triglyceride, high density lipoprotein cholesterol, and glucosc. Disodium edetate $(2 \cdot 7 \mathrm{mmol} / \mathrm{l})$ was used as an anticoagulant. In Glasgow, Leicester, and Oxford fasting blood samples were taken, but this was not possible in London because the clinics were in the afternoon.

Cholesterol and triglyceride concentrations were measured by automated enzymatic procedures with standard enzyme kits in all four centres (cholesterol kit 236691, cholesterol oxidase/peroxidase-aminophenazone; triglyceride kit 701904, glycerol phosphate oxidase/peroxidaseaminophenazone; Boehringer, Germany). High density lipoprotein cholesterol concentration was measured by differential precipitation with heparin and $92 \mathrm{mM}$ manganese chloride. ${ }^{7}$ In Oxford a further step with sodium dodecylsulphate was used to precipitate very low density lipoprotein so that low density lipoprotein cholesterol concentration could be calculated by subtraction. ${ }^{8}$ The Friedewald equation was used to calculate low density lipoprotein cholesterol concentration in all centres. ${ }^{9}$ The correlation coefficient $(r)$ between measured and calculated concentrations in the data from Oxford was 0.94 . Quality control was assessed by distribution of aliquots of plasma samples to all four laboratories, the sample itself being traceable to the lipid standardisation programme of the Centers for Disease Control, Atlanta, Georgia, United States. During the study overall the percentage differences from the mean in the four centres were $2 \cdot 2-3 \cdot 6$ for cholesterol; $3 \cdot 0-5 \cdot 5$ for triglyceride, and $3 \cdot 0-8 \cdot 9$ for high density lipoprotein cholesterol.

\section{MANAGEMENT OF DATA AND STATISTICAL METHODS}

Data were recorded on standard forms and identified only by accession number when transmitted to a data processing centre. Data were checked as they were entered into the computer database. In addition, checking programs were run at intervals and doubtful entries verified against the hard copies held at the lipid clinics. Statistical analyses were performed using analysis of variance and covariance techniques for continuous variables adjusting for age differences among centres and the $\chi^{2}$ test for independence. Log transformations of the lipid measurements were used in the analyses as they seemed to resemble more closely the normal distribution.

\section{Results}

\section{DISTRIBUTION OF BLOOD LIPID CONCENTRATIONS}

The mean total cholesterol concentration was $5.9(\mathrm{SD} \mathrm{l} \cdot 2) \mathrm{mmol} / \mathrm{l}$ in men and $5 \cdot 8(1 \cdot 2) \mathrm{mmol} / \mathrm{l}$ in women. The mean value for men and women in
London was $5.5(1.2) \mathrm{mmol} / \mathrm{l}$, which was significantly lower $(\mathrm{p}<0.05)$ than that in the other centres, among which no significant differences were found (Oxford: men 5.9 (1.1), women 5.7 (1.1); Leicester: men 6.1 (1.3), women $6.0(1.3)$; Glasgow: men $5.8(1 \cdot 2)$, women $5.9(1 \cdot 2))$. Although concentrations in men and women were similar overall, the trends with age were noticeably different in the two sexes. In table II the data for the four centres are combined as identical trends were seen in each centre. In the youngest age category (25-29) concentrations were similar in men and women. Thereafter values increased in men until the 45-49 age band, after which no further increase was observed. By contrast, concentrations in women rose only slightly until the age of 40-44 years, after which they increased steeply such that in the two oldest five year age groups mean concentrations were higher in women than in men. Mean concentrations of calculated low density lipoprotein cholesterol showed similar trends. High density lipoprotein cholesterol concentrations did not, however, vary among the centres or with age. Women had consistently higher concentrations than men, mean values being $1.6(0.4)$ and $1.4(0.4) \mathrm{mmol} / \mathrm{l}$, respectively $(\mathrm{p}<0.01)$

TABLE II-Mean (SD) plasma total cholesterol and calculated low density lipoprotein cholesterol concentrations (mmol/l) by age and sex

\begin{tabular}{cccccc}
\hline \multirow{2}{*}{$\begin{array}{c}\text { Age group } \\
\text { (years) }\end{array}$} & \multicolumn{2}{c}{ Total cholesterol } & & \multicolumn{2}{c}{ Calculated low density lipoprotein cholesterol } \\
\cline { 2 - 3 } \cline { 5 - 6 } \cline { 5 - 5 } & Men & Women & & Men & Women \\
\hline $25-29$ & $5 \cdot 2(1 \cdot 1)$ & $5 \cdot 1(1 \cdot 0)$ & & $3 \cdot 2(1 \cdot 1)$ & $3 \cdot 0(0 \cdot 9)$ \\
$30-34$ & $5 \cdot 5(1 \cdot 1)$ & $5 \cdot 2(1 \cdot 0)$ & & $3 \cdot 3(1 \cdot 1)$ & $3 \cdot 1(1 \cdot 0)$ \\
$35-39$ & $5 \cdot 8(1 \cdot 2)$ & $5 \cdot 3(1 \cdot 0)$ & & $3 \cdot 6(1 \cdot 1)$ & $3 \cdot 2(1 \cdot 0)$ \\
$40-44$ & $6 \cdot 0(1 \cdot 2)$ & $5 \cdot 6(1 \cdot 1)$ & & $3 \cdot 8(1 \cdot 1)$ & $3 \cdot 4(1 \cdot 0)$ \\
$45-49$ & $6 \cdot 1(1 \cdot 2)$ & $5 \cdot 9(1 \cdot 2)$ & & $3 \cdot 8(1 \cdot 1)$ & $3 \cdot 7(1 \cdot 0)$ \\
$50-54$ & $6 \cdot 1(1 \cdot 2)$ & $6 \cdot 4(1 \cdot 1)$ & & $3 \cdot 9(1 \cdot 1)$ & $4 \cdot 0(1 \cdot 1)$ \\
$55-59$ & $6 \cdot 1(1 \cdot 2)$ & $6 \cdot 7(1 \cdot 2)$ & & $3 \cdot 9(1 \cdot 1)$ & $4 \cdot 3(1 \cdot 2)$
\end{tabular}

Triglyceride concentrations were significantly higher in men than in women $(1.8(1.4) v 1.3(0.9) \mathrm{mmol} / \mathrm{l})$, respectively; $\mathrm{p}<0.01)$. The trends with age for men and women were similar to those observed for plasma cholesterol and low density lipoprotein cholesterol, except that at no age did women achieve higher concentrations than men (table III). In both men and women, mean triglyceride concentrations were significantly higher $(\mathrm{p}<0.05)$ in Glasgow and London than in Leicester and Oxford (Glasgow: men $1.9(1.5)$, women $1.5(1 \cdot 2)$; London: men $2.0(1.6)$, women $1.5(0.9)$; Leicester: men $1 \cdot 7(1 \cdot 2)$, women $1 \cdot 1(0 \cdot 7)$; Oxford: men $1 \cdot 6(1 \cdot 1)$, women $1 \cdot 2(0 \cdot 7))$.

TABLE III-Mean (SD) plasma triglyceride concentrations ( $\mathrm{mmol} / \mathrm{l})$ by age and sex in three centres where fasting blood samples were obtained $^{\star}$

\begin{tabular}{|c|c|c|}
\hline Age group (years) & Men & Women \\
\hline $25-29$ & $1.4(1.0)$ & $1 \cdot 1(0.6)$ \\
\hline $30-34$ & $1.6(1.3)$ & $1.1(0.6)$ \\
\hline $35-39$ & $1.7(1.2)$ & $1.1(0.7)$ \\
\hline $40-44$ & $1.8(1.7)$ & $1.2(1.0)$ \\
\hline 45.49 & $1.9(1.4)$ & $1.4(0.9)$ \\
\hline $50-54$ & $1.9(1.5)$ & $1.5(0.9)$ \\
\hline $55-59$ & $1.9(1.2)$ & $1.7(1.3)$ \\
\hline
\end{tabular}

^Excludes London.

FASTING GLUCOSE CONCENTRATIONS, BODY MASS INDICES, AND BLOOD PRESSURE MEASUREMENTS

Table IV shows mean fasting glucose concentrations, body mass indices, and systolic and diastolic blood pressure measurements. Glucose concentrations increased with age $(p<0.01)$ and were slightly but significantly higher in men $(p<0 \cdot 01)$. Systolic and diastolic blood pressures showed similar increases with age and were higher in men than in women up to the age of 54 . Thereafter values were similar in men and women. Body mass index did not differ significantly in men and women, but in women and not men the index tended to increase with age.

In Glasgow and London body mass index (25.3 (4.3) and 25.4 (4.5), respectively) was higher than in Oxford and Leicester $(24.7$ (3.7) and 24.5 $(3 \cdot 6)$, respectively). Body mass index showed a low grade but significant correlation $(\mathrm{r}=0.3, \mathrm{p}<0.01)$ with systolic and diastolic blood pressures and 
triglyceride concentration. This could account for the higher systolic and diastolic blood pressures and triglyceride concentrations in Glasgow and London than in Oxford and Leicester (see table VII).

\section{SMOKING HABITS}

Men smoked more than women, and younger men and women smoked less than older people in each centre (table V). Table VI shows the regional variation in smoking habits. Patients in Glasgow smoked significantly more than those in other centres $(\mathrm{p}<0 \cdot 01)$.

\section{PREVALENCES OF RISK FACTORS}

Table VII shows the prevalence of hypercholesterolaemia (with various cut off points); hypertension (defined as systolic or diastolic blood pressure greater than 160 and $90 \mathrm{~mm} \mathrm{Hg}$, respectively); a family history of coronary heart disease; diabetes (defined as diagnosed diabetes being treated with diet, tablets, or insulin or a fasting blood glucose concentration $>7 \mathrm{mmol} / \mathrm{l}$ in someone in whom diabetes had not been diagnosed); and obesity (body mass index $>25$ ).

\section{COMPARISON OF CASE FINDING TECHNIQUES FOR DETECTING HYPERCHOLESTEROLAEMIA}

Hypercholesterolaemia differs from most cardiovascular risk factors in that it requires analysis of blood to be detected. The risk of coronary heart disease is proportionally associated with increasing concentrations of cholesterol, and it is therefore difficult to establish cut off points in defining hypercholesterolaemia. For the purpose of assessing effectiveness of various criteria for selective case finding, however, we chose cut off points of 6.5 and $8.0 \mathrm{mmol} / \mathrm{l}$ (table VIII). These concentrations are widely recognised as

TABLE IV-Mean (SD) fasting blood glucose concentrations, body mass indices, and blood pressure measurements by age and sex

\begin{tabular}{|c|c|c|c|c|c|c|c|c|}
\hline \multirow[b]{3}{*}{ Age group (years) } & & & & & \multicolumn{4}{|c|}{ Blood pressure (mm $\mathrm{Hg}$ ) } \\
\hline & \multicolumn{2}{|c|}{ Fasting glucose $(\mathrm{mmol} / \mathrm{l})^{\star}$} & \multicolumn{2}{|c|}{ Body mass index $\left(\mathrm{kg} / \mathrm{m}^{2}\right)$} & \multicolumn{2}{|c|}{ Systolic } & \multicolumn{2}{|c|}{ Diastolic } \\
\hline & Men & Women & Men & Women & Men & Women & Men & Women \\
\hline $\begin{array}{l}25-34 \\
35-44 \\
45-54 \\
55-59\end{array}$ & $\begin{array}{l}4.5(0.9) \\
4.6(1 \cdot 1) \\
4.8(1 \cdot 2) \\
5.0(1 \cdot 3)\end{array}$ & $\begin{array}{l}4.4(0.8) \\
4 \cdot 5(0 \cdot 7) \\
4 \cdot 7(1 \cdot 1) \\
4 \cdot 8(1 \cdot 2)\end{array}$ & $\begin{array}{l}24.3(3.4) \\
25.0(3.6) \\
25.6(3.4) \\
25.6(3.3)\end{array}$ & $\begin{array}{l}23 \cdot 7(4 \cdot 2) \\
24 \cdot 4(4 \cdot 2) \\
25 \cdot 4(4 \cdot 5) \\
26 \cdot 0(4 \cdot 6)\end{array}$ & $\begin{array}{l}124 \cdot 4(13 \cdot 8) \\
125 \cdot 9(15 \cdot 7) \\
131 \cdot 7(17 \cdot 9) \\
138 \cdot 5(20 \cdot 1)\end{array}$ & $\begin{array}{l}116 \cdot 8(13 \cdot 8) \\
120 \cdot 3(15 \cdot 7) \\
129 \cdot 6(18 \cdot 2) \\
139 \cdot 1(21 \cdot 3)\end{array}$ & $\begin{array}{l}77 \cdot 4(10 \cdot 1) \\
80 \cdot 5(11 \cdot 2) \\
83 \cdot 7(11 \cdot 5) \\
85 \cdot 2(12 \cdot 2)\end{array}$ & $\begin{array}{l}73.7(10.0) \\
75.9(10.1) \\
80.8(11.3) \\
84.4(12.0)\end{array}$ \\
\hline
\end{tabular}

$\star$ Values not available for London.

TABLE V-Smoking habits in men and women of different ages. Values are numbers (percentages) of subjects from all four centres

\begin{tabular}{|c|c|c|c|c|c|c|c|c|}
\hline & \multicolumn{2}{|c|}{$25-34$} & \multicolumn{2}{|c|}{$35-44$} & \multicolumn{2}{|c|}{$45-54$} & \multicolumn{2}{|c|}{$55-59$} \\
\hline Non-smokers & $557(47)$ & $661(52)$ & $699(37)$ & $1118(53)$ & $626(34)$ & $1075(53)$ & $231(28)$ & $404(51)$ \\
\hline Ex-smokers & $198(17)$ & $180(14)$ & $479(25)$ & $377(18)$ & $521(28)$ & $297(15)$ & $246(30)$ & $156(20)$ \\
\hline $15-24$ & $196(17)$ & $219(17)$ & $270(14)$ & $309(15)$ & $260(14)$ & $310(15)$ & $124(15)$ & $118(15)$ \\
\hline$\geqslant 25$ & $84(7)$ & $50(4)$ & $146(8)$ & $84(4)$ & $116(6)$ & $96(5)$ & $61(7)$ & 17 (2) \\
\hline Pipe or cigar smokers & $37(3)$ & $1(0 \cdot 1)$ & $154(8)$ & $5(0 \cdot 2)$ & $161(9)$ & $4(0 \cdot 2)$ & $69(8)$ & \\
\hline
\end{tabular}

TABLE VI-Regional variation in smoking habits. Values are numbers (percentages) of subjects studied in each centre

\begin{tabular}{|c|c|c|c|c|}
\hline & Oxford $(n=3988)$ & Leicester $(n=2555)$ & Glasgow $(n=3663)$ & London $(n=1764)$ \\
\hline Ex-smokers & $1099(28)$ & $640(25)$ & $495(14)$ & $232(13)$ \\
\hline \multicolumn{5}{|c|}{ Cigarette smokers (No of cigarettes/day): } \\
\hline $5-14$ & $249(6)$ & $155(6)$ & $393(11)$ & 155 (9) \\
\hline $15-24$ & $333(8)$ & $232(9)$ & $924(25)$ & $318(18)$ \\
\hline$\geqslant 25$ & 88 (2) & $65(3)$ & $374(10)$ & $130(7)$ \\
\hline Pipe or cigar smokers & $172(4)$ & $106(4)$ & $107(3)$ & 47 (3) \\
\hline
\end{tabular}

TABLE VII-Prevalence of various risk factors for coronary heart disease in each centre. Values are numbers (percentages) of subjects

\begin{tabular}{|c|c|c|c|c|c|c|c|c|c|c|}
\hline \multirow[b]{2}{*}{ Risk factor } & \multicolumn{2}{|c|}{ Oxford } & \multicolumn{2}{|c|}{ Leicester } & \multicolumn{2}{|c|}{ Glasgow } & \multicolumn{2}{|c|}{ London } & \multicolumn{2}{|c|}{ Total } \\
\hline & 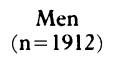 & $\begin{array}{c}\text { Women } \\
(n=2094)\end{array}$ & $\underset{(n=1243)}{\text { Men }}$ & $\begin{array}{c}\text { Women } \\
(n=1333)\end{array}$ & $\begin{array}{c}\text { Men } \\
(n=1843)\end{array}$ & $\begin{array}{l}\text { Women } \\
(\mathrm{n}=1881)\end{array}$ & $\underset{(n=843)}{\text { Men }}$ & $\begin{array}{c}\text { Women } \\
(n=943)\end{array}$ & $\underset{(n=5841)}{\operatorname{Men}}$ & $\begin{array}{l}\text { Women } \\
(n=6251)\end{array}$ \\
\hline \multicolumn{11}{|l|}{ Hypercholesterolaemia: } \\
\hline Cholesterol $>8.0 \mathrm{mmol} / 1$ & $71(4)$ & $69(3)$ & $88(7)$ & $85(6)$ & $70(4)$ & $87(5)$ & $23(3)$ & $29(3)$ & $252(4)$ & $270(4)$ \\
\hline Cholesterol $>6.5 \mathrm{mmol} / \mathrm{l}$ & $487(26)$ & $440(21)$ & $412(33)$ & $365(27)$ & $453(25)$ & $496(26)$ & $146(17)$ & $184(20)$ & $1498(26)$ & $1485(24)$ \\
\hline Cholesterol $>5.5 \mathrm{mmol} / \mathrm{l}$ & $1168(61)$ & $1055(50)$ & $806(65)$ & $766(58)$ & $1033(56)$ & $1076(57)$ & $355(42)$ & $412(44)$ & $3362(58)$ & $3309(53)$ \\
\hline Hypertension & $265(14)$ & $173(8)$ & $151(12)$ & $99(7)$ & $304(17)$ & $223(12)$ & $125(15)$ & $110(12)$ & $845(15)$ & $605(10)$ \\
\hline Family history of coronary heart disease & $669(35)$ & $817(39)$ & $540(43)$ & $580(44)$ & $673(37)$ & $808(43)$ & $193(23)$ & $259(28)$ & $2075(36)$ & $2464(40)$ \\
\hline Diabetes & $15(1)$ & $14(1)$ & $23(2)$ & $12(1)$ & $27(2)$ & $10(1)$ & $5(1)$ & $6(1)$ & $70(1)$ & $42(1)$ \\
\hline Obesity & $905(47)$ & $672(32)$ & $518(42)$ & $382(29)$ & $857(47)$ & $857(46)$ & $399(47)$ & $415(44)$ & $2679(46)$ & $2326(37)$ \\
\hline
\end{tabular}


TABLE VIII-Effectiveness in detecting hypercholesterolaemia (cholesterol values $>6.5$ or 8.0 mmol/l) with different criteria for selective screening

\begin{tabular}{|c|c|c|c|c|c|}
\hline \multirow[b]{2}{*}{ Screening criterion } & \multirow[b]{2}{*}{$\begin{array}{l}\text { No }(\%) \text { of study population } \\
\text { with screening criterion }{ }^{\star}\end{array}$} & \multicolumn{2}{|c|}{ Cholesterol $>6.5 \mathrm{mmol} / \mathrm{l}$} & \multicolumn{2}{|c|}{ Cholesterol $>8.0 \mathrm{mmol} / \mathrm{l}$} \\
\hline & & $\begin{array}{c}\text { No }(\%) \dagger \text { of subjects } \\
(n=2992)\end{array}$ & $\begin{array}{l}\text { No as \% of subjects } \\
\text { with screening criterion }\end{array}$ & $\begin{array}{c}\text { No }(\%)+\text { of subjects } \\
(n=528)\end{array}$ & $\begin{array}{c}\text { No as } \% \text { of subjects } \\
\text { with screening criterion }\end{array}$ \\
\hline Family history of coronary heart disease & $4556(38)$ & $1323(44)$ & 29 & $264(50)$ & 6 \\
\hline Family history of coronary heart disease under age 50 & $1046(9)$ & $304(10)$ & 29 & $62(12)$ & 6 \\
\hline Corneal arcus & $723(6)$ & $287(10)$ & 40 & $68(13)$ & 9 \\
\hline Xanthoma or xanthelasma & $311(3)$ & $116(4)$ & 37 & $26(5)$ & 8 \\
\hline Obesity $(B M I>25)$ & $5023(43)$ & $1607(54)$ & 32 & $283(54)$ & 6 \\
\hline Hypertension $(\mathrm{BP}>160 / 90 \mathrm{~mm} \mathrm{Hg})$ & $1454(12)$ & $554(19)$ & 38 & $109(21)$ & 8 \\
\hline Family history of obesity & $7519(64)$ & $2200(74)$ & 29 & $404(77)$ & 5 \\
\hline Any of the above criteria & $7918(66)$ & $2328(78)$ & 29 & $424(80)$ & 5 \\
\hline
\end{tabular}

* Some values are missing.

†Proportion of all subjects with defined hypercholesterolaemia who would have been detected by each screening criterion.

BMI = Body mass index.

$\mathrm{BP}=$ Blood pressure.

representing a significant and considerable increased risk of coronary heart disease and are comparable with cut off points suggested by international and British organisations. ${ }^{111}$ Table VIII shows that if only subjects with a family history of coronary heart disease (at any age) were screened $44 \%$ of those with cholesterol concentrations $>6.5 \mathrm{mmol} / 1$ and $50 \%$ of those with concentrations $>8.0 \mathrm{mmol} / \mathrm{l}$ would be detected, but if this were the only screening criterion $38 \%$ of the study population would have to be screened. Obesity is the only other potential criterion likely to identify a relatively high proportion of subjects with hypercholesterolaemia. Measuring lipid concentrations in obese subjects or those with a family history of coronary heart disease would identify up to three quarters of those with hypercholesterolaemia (depending on the extent that these coexisted in each subject), but with these two criteria about $66 \%$ of the population would have to be tested. None of the criteria has high specificity.

COMPARISON OF DATA FROM PATIENTS RECRUITED BY DIFFERENT METHODS AND BETWEEN RESPONDERS AND THOSE NOT INITIALLY RESPONDING TO A WRITTEN INVITATION

No significant differences were found in the data collected by opportunistic case finding and random selection-for example, overall mean total cholesterol concentration was $5.9(1.4)$ and $5.8(1.4) \mathrm{mmol} / \mathrm{l}$ by opportunistic case finding and random selection, respectively. Similarly, no significant differences were found when the two approaches were compared in individual centres or men and women were considered separately. In those practices where two invitations were issued to potential participants concentrations were almost identical in those responding to the first and to the follow up invitation (mean total cholesterol concentrations $5 \cdot 9(1 \cdot 2)$ and $5 \cdot 8(1 \cdot 2) \mathrm{mmol} / \mathrm{l}$, respectively).

\section{Discussion}

Clearly any large epidemiological study cannot achieve a $100 \%$ rate of response and it is important to consider whether the overall rate of response in our study was enough to give an accurate estimate of plasma lipid concentrations in the community. Although subjects with lower concentrations might be less likely to come forward, we think that this probably would not have appreciably influenced our results. The main justification for this assumption is the similarity of concentrations in subjects selected at random who responded to the first and to the follow up invitation. The finding of almost identical distributions of plasma lipid concentrations in subjects selected by opportunistic case finding and random selection (which might have been expected to identify different populations) provides further reassurance.

The finding of mean cholesterol concentrations of 5.9 and $5.8 \mathrm{mmol} / \mathrm{l}$ in British men and women aged 25-59 years suggests that little or no change in plasma cholesterol concentration in the population has occurred during the past 12 years. These values are almost identical with those found by Lewis et al in $1974^{1}$ and those reported from the regional heart study in 1978-80, in which men aged 40-59 had mean concentrations of $6.3 \mathrm{mmol} / \mathrm{l}$; in men of similar age we found a mean value of $6 \cdot 1 \mathrm{mmol} / \mathrm{l}$. This finding is disappointing in view of the attempts that have been made to encourage the population to adopt dietary changes to lower blood cholesterol concentration. These results suggest one reason why mortality from coronary heart disease in Britain has decreased much less than that in many other countries. Mortality in the United States, Finland, New Zealand, and Australia has fallen, and evidence from the United States suggests that this is accompanied by a decrease in plasma cholesterol concentrations. ${ }^{12}{ }^{13}$ In Britain cholesterol concentrations do not seem to account for the appreciably higher mortality from coronary heart disease in Scotland as values in Glasgow were no higher than in England, though they were significantly lower in London.

Our study also confirms data on the epidemiology of plasma lipid and lipoprotein concentrations. The absence of an overall difference with sex conceals the fact that younger women, especially those aged 30-44 years, have lower concentrations than men, whereas after the age of 50 women have appreciably higher concentrations than men. Differences with age and sex in total cholesterol concentration are accounted for by variation in low density lipoprotein cholesterol values. Although high density lipoprotein cholesterol concentrations were higher in women than in men, they showed no relation to age. Triglyceride concentrations showed similar trends with age in men and women to those seen for cholesterol, but at no age were values in women as high as in men. These findings are similar to those reported from Britain and North America. ${ }^{1+15}$ Of the other risk factors studied, smoking showed the most striking regional variation. Men and women in Glasgow were more likely to be smokers than those in the English centres, and those who smoked tended to smoke more heavily. Glaswegians and Londoners were more obese than participants from Oxford and Leicester, and this obesity was associated with higher blood pressure. The interactive effect of smoking, obesity, and hypertension could contribute to the higher rates of coronary heart disease in Glasgow. The slightly higher triglyceride concentrations and blood pressure measurements in London than in the other English centres could be explained by the fact that the subjects in London had not been fasting when the blood sample was taken.

The similarity of plasma lipid concentrations and the prevalence of other cardiovascular risk factors in the groups selected by opportunistic case finding and random selection also affects strategies for preventing early coronary heart disease. There are two main approaches. The population strategy aims at reducing the prevalence of risk factors in the community; it is based on the observation that a large proportion of the population in countries with high rates of coronary heart disease is at some risk of developing the disease and that most cases occur in people with only moderately raised lipid concentrations and prevalences of other risk factors. The high risk strategy, however, is aimed at people at particularly high risk who are identified because their values for risk factors are greater than arbitrarily defined cut off points. Each approach has merits and disadvantages, and we think that both should be applied in countries at high risk. ${ }^{6}$ Clearly, in Britain health education (population strategy), whose aim was to persuade the public to change its diet and life style to reduce the risk of cardiovascular disease, had had little impact on plasma lipid 
concentrations. Dietary recommendations are primarily aimed at achieving lower cholesterol concentrations, ${ }^{16}$ but values in the population have changed little during the past 12 years.

Techniques for implementing the population strategy need re-examining. Our results also endorse the complementary role of the high risk strategy, which enables advice to be targeted at those who will benefit most from it. ${ }^{6}$ Around 5\% of the population studied were at high risk with respect to serum total cholesterol concentrations, having values greater than $7 \cdot 8 \mathrm{mmol} / \mathrm{l}$, a concentration that is regarded by the European Atherosclerosis Society as needing active treatment. ${ }^{10}$ This proportion of the population includes most patients with major inherited diseases such as familial hypercholesterolaemia and remnant (type III) hyperlipoproteinaemia. A quarter of the population has concentrations exceeding $6.5 \mathrm{mmol} / \mathrm{l}$, which is also associated with a pronounced increase in risk of premature coronary heart disease; many subjects in this group also require individual care especially when multiple risk factors coexist." "Similarly, the prevalence of other risk factors gives cause for concern.

The importance of determining risk factor state in primary care is widely accepted, and this study confirms that the opportunistic approach to such case finding is as effective as, and more efficient than, random screening of the population in detecting those at risk. Uptake of the invitation to the health check was exceptionally high, and as a large proportion of the population will probably visit their general practitioner within five years ${ }^{17}$ offers to assess risk factors at such visits provide an optimal basis for case finding. The work load will be diffused over several years. Recognising risk factors in a clinical setting provides an ideal basis for their management. Opportunistic examination eliminates the considerable administrative costs of random screening, when an appreciable proportion of those invited may not attend. The yield in terms of the rate at which those at high risk are identified is similar.

Various approaches to identifying and treating those risk factors traditionally managed in general practice (smoking, hypertension, and obesity) have been well described. ${ }^{18}$ Less attention has been given to the detection of hyperlipidaemia. Many think that screening for hyperlipidaemia should be carried out selectively with markers such as a known family history of premature coronary heart disease or signs of hypercholesterolaemia such as corneal arcus, xanthomas, and xanthelasmas. The data in table VIII show that none of the criteria for screening is particularly sensitive or specific. To detect most people with serious hyperlipidaemia in the population would entail testing two thirds of the community according to criteria for selective screening. Thus a need for non-selective case finding by opportunistically assessing risk factors clearly exists. This method may be facilitated by equipment allowing cheap measurement of plasma cholesterol concentration within minutes after a blood sample is taken from a pin prick. Until this has become widely available lipid concentrations should be measured in subjects with a family history of coronary heart disease and obesity (body mass index $>25$ ) as these criteria are relatively sensitive and detect the highest proportion of subjects with hypercholesterolaemia, even though as markers for hypercholesterolaemia they have low specificity. Lipid concentrations should also be measured in those with corneal arcus or xanthomas and xanthelasmas and those with hypertension, as these characteristics are are comparatively specific. Of course cholesterol concentrations do not need to be measured in subjects who have been fasting. In addition, that mean triglyceride values in London did not differ appreciably from the other centres suggests that, provided a large meal has not been eaten just before blood is sampled, triglyceride concentrations can be measured in a nonfasting sample in the morning or afternoon without great error. Fasting triglyceride concentration should be measured in those with raised values in a repeat test.

We thank Bristol Myers Pharmaceuticals for financial support and the Regional Health Promotion Fund of Oxford Regional Health Authority and the Simon Broome Heart Research Trust for supporting the Oxford centre. We also thank the study coordinators, Ms Anne Parfitt (London), Dr A P Wojciechowski (Leicester), and Ms Moira Devine (Glasgow), and the medical laboratory scientific officers, Messrs R Carter, L Benfield (Oxford), A La Ville, M Shaikh (London), J Mahabir, A Fenton (Leicester), and N Caine (Glasgow). Finally we thank all the general practitioners who participated. In Leicester they were Drs A K Moore, B Lightstone, $\mathrm{R}$ Dziewanowski, R Ellis, W Harrison, and G Martin (Nuneaton); in London Drs C C Mahendra, T A Joseph, A R Anderson, K M McFadyen, J Spindler, G Dickinson, M J F Courteney, H A R Dawson, L A Ruben, R F Goulston, R A Savage, J Hitchins, B D Salt, R S Church, H K P Lee, P Southwell, K Panama, and S S Wickremasinghe; in Oxford Drs G E Sacks and partners, M L Bowen and partners, C Sherlock, A D Cole and partners, P G Kay and partners, L Grainger and partners; and in Glasgow Dr C S S MacKelvie.

\section{References}

1 Lewis B, Chait A, Wootton IDP, et al. Frequency of risk factors for ischaemic heart disease in a healthy British population. Lancet 1974; i:141-6.

2 Rose G, Heller RF, Tunstall Pedoe H, Christie DGS. Heart disease prevention project: a randomised controlled trial in industry. BrMed $\mathcal{F}$ 1980;280:747-51.

3 Reid DD, Hamilton PJS, McCartney P, Rose G. Smoking and other risk factors for coronary heart disease in British civil servants. Lancet 1976;ii:979-84.

4 Thompson GR, Robinson D, Allaway SL, Bevan EA, Ritchie CD. Prevalence of hyperlipidaemia in British compared with North American men. In: Schierf G, Morl H, eds. Expanding horizon in atherosclerosis research. Berlin: Springer Verlag, 1987:114-21.

5 Schelle DS, Shaper AG, Whitehead TP, Bullock DG, Ashby D, Patel I. Blood lipids in middleaged British men. Br Heart I 1983;49:205-13.

6 Lewis B, Mann JI, Mancini M. Reducing the risks of coronary heart disease in individuals and in the population. Lancet 1986;i:956-60.

7 Burstein M, Scholnick HR, Morfin R. Rapid method for the isolation of lipoproteins from human serum by precipitation with polyanions. $\mathcal{F}$ Lipid Res 1970;11:583-95.

8 Ononogbu IC, Lewis B. Lipoprotein fractionation by a precipitation method. A simple quantitative procedure. Clin Chim Acta 1976;71:397-402.

9 Friedewald WT, Levy RI, Fredickson DS. Estimation of the concentration of low density lipoprotein cholesterol in plasma without use of the preparative ultracentrifuge. Clin Chem 1972;18:499-502.

10 Study Group, European Atherosclerosis Society. Strategies for the prevention of coronary heart disease: a policy statement of the European Atherosclerosis Society. Eur Heart $\mathcal{f}$ 1987;8:77-88.

11 Shepherd J, Betterridge DJ, Durrington P, et al. Strategies for reducing coronary heart disease and desirable limits for blood lipid concentrations: guidelines of the British Hyperlipidaemi Association. BrMed f 1987;295:1245-6.

12 Stamler $\mathrm{J}$. The marked decline in coronary heart disease mortality in the United States, 1968-1981; summary of findings and possible explanations. Cardiology 1985;72:11-22.

13 Pyorala K, Salonen JT, Valkonen T. Trends in coronary heart disease mortality and morbidity and related factors in Finland. Cardiology 1985;72:35-51.

14 Thorogood M, Carter R, Benfield L, McPherson K, Mann JI. Plasma lipid lipoprotein cholestero concentrations in people with different diets in Britain. Br Med $\mathcal{F}$ 1987;295:351-3.

15 Heiss G, Tamir I, Davis CE, et al. Lipoprotein-cholesterol distributions in selected North American populations: the lipid research clinics program prevalence study. Circulation 1980;61:302-15.

16 Department of Health and Social Security. Diet and cardiovascular disease. London: HMSO, 1984 (Report on health and social subjects No 28 .

17 Fowler G. The general practitioner's role in the prevention of coronary heart disease. The Practitioner 1986;230:859-964.

18 Fullard E, Fowler G, Gray M. Promoting prevention in primary care: controlled trial of low technology, low cost approach. Br Med f 1987;294:1080-2.

(Accepted 25 February 1988)

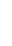

